\title{
ON THE CONTINUITY OF THE VECTOR VALUED AND SET VALUED CONDITIONAL EXPECTATIONS
}

\author{
NIKOLAOS S. PAPAGEORGIOU \\ University of California \\ 1015 Department of Mathematics \\ Davis, California 95616 \\ (Recelved May 12, 1988 and in revised form January 29, 1989)
}

ABSTRACT. In this paper we study the dependence of the vector valued conditional expectation (for both single valued and set valued random variables), on the $\sigma$-field and random variable that determine it. So we prove that it is continuous for the $L^{1}(X)$ convergence of the sub- $\sigma$-fields and of the random variables. We also present a sufficient condition for the $\mathrm{L}^{1}(\mathrm{X})$-convergence of the sub- $\sigma$-fields. Then we extend the work to the set valued conditional expectation using the Kuratowski-Mosco ( $\mathrm{K}-\mathrm{M})$ convergence and the convergence in the $\Delta$-metric. We also prove a property of the set valued conditional expectation.

KEY WORDS AND PHRASES. Conditional expectation, $\mathrm{L}^{1}(\mathrm{X})$ convergence of sub- $\sigma-$ fields, Hausdorff metric, Kuratowski-Mosco convergence, integrable selectors, Rädstrom embedding theorem.

1980 A.M.S. CLASSIFICATION CODE: 60B11

\section{1) INTRODUCTION}

The purpose of this note is to study the dependence of the vector valued conditional expectation (for single valued and multivalued random variables), on the two quantities that define it. Namely on the sub- $\sigma$-field and on the random variable.

Let $(\Omega, \Sigma, \mu)$ be a complete probability space and $\mathrm{X}$ a Banach space. The following are well known for $\mathrm{X}$-valued random variables:

(a) If $\mathrm{f} \epsilon \mathrm{L}^{1}(\mathrm{X}),\left\{\Sigma_{\mathrm{n}}\right\}_{\mathrm{n} \geq 1}$ is an increasing (decreasing) sequence of sub- $\sigma$-fields and $\hat{\Sigma}=\underset{i \mathbf{i} \geq 1}{\vee} \Sigma_{n}\left(\hat{\Sigma}=\bigcap_{\bar{n} \geq 1} \Sigma_{n}\right)$

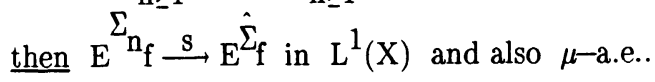


This theorem, known in the literature as the "Neveu-Ionescu Tulcea theorem", can be found in Neveu [8], proposition $v-2-6$. It is a particular case of the "martingale convergence theorem" (see Metivier [7], corollary 11.8).

(b) If $\mathrm{f}_{\mathrm{n}} \stackrel{\mathrm{s}}{\longrightarrow} \mathrm{f}$ in $\mathrm{L}^{1}(\mathrm{X})$ and $\Sigma_{0}$ is a sub- $\sigma$-field of $\Sigma$, then $\mathrm{E}^{\Sigma_{\mathrm{f}_{\mathrm{n}}}} \stackrel{\mathrm{s}}{\rightarrow} \mathrm{E}^{\Sigma_{0}}$ in $\mathrm{L}^{1}(\mathrm{X})$.

This is a consequence of the fact that the vector valued conditional expectation is a continuous, linear operator on $\mathrm{L}^{1}(\mathrm{X})$ (see Neveu [8]).

Combining (a) and (b) above, it is easy to see that the following is true:

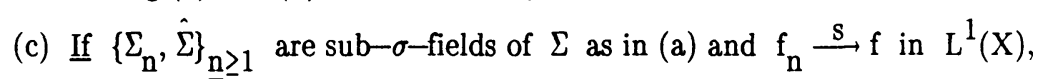

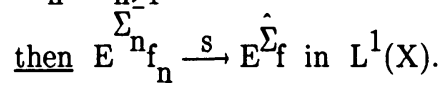

In this paper, we examine what happens if the sequence $\left\{\Sigma_{n}\right\}_{n \geq 1}$ of sub- $\sigma$-fields of $\Sigma$ is not necessarily monotone increasing. Our work extends those of D.N. Nghiem [9] and Fetter [3], who dealt with single valued random variables with values in $\mathbb{R}$.

\section{2) PRELIMINARIES}

Let $(\Omega, \Sigma, \mu)$ be a complete probability space and $\mathrm{X}$ a separable Banach space. We will be using the following notations:

$$
\mathrm{P}_{\mathrm{f}(\mathrm{c})}(\mathrm{X})=\{\mathrm{A} \subseteq \mathrm{X}: \text { nonempty, closed, (convex) }\}
$$

and $\quad P_{(w) k(c)}(X)=\{A \subseteq X:$ nonempty, (w-) compact, (convex) $\}$.

Also if $\mathrm{A} \in 2^{\mathrm{X}} \backslash\{\emptyset\}$, we define $|\mathrm{A}|=\sup \{\|\mathrm{x}\|: \mathrm{x} \in \mathrm{A}\} \quad$ ("norm" of $\left.\mathrm{A}\right), \sigma\left(\mathrm{x}^{*}, \mathrm{~A}\right)$ $\left.=\sup \left\{x^{*}, x\right): x \in A\right\} x^{*} \epsilon X^{*}$ (support function of $A$ ) and for every $z \epsilon X, d(z, A)$ $=\inf \{\|z-x\|: x \in A\}$ (distance function from $A$ ).

A multifunction $F: \Omega \rightarrow P_{f}(X)$ is said to be measurable, if for all $z \in X$, $\omega \rightarrow \mathrm{d}(\mathrm{z}, \mathrm{F}(\omega))$ is measurable. Other equivalent definitions of measurability of a multifunction can be found in Wagner [14].

By $S_{F}^{1}$ we will denote the set of integrable selectors of $F(\cdot)$. So:

$$
\mathrm{S}_{\mathrm{F}}^{1}=\left\{\mathrm{f}(\cdot) \epsilon \mathrm{L}^{1}(\mathrm{X}): \mathrm{f}(\omega) \epsilon \mathrm{F}(\omega) \mu \text {-a.e. }\right\}
$$

It is easy to show that $S_{F}^{1}$ is nonempty if and only if $\inf \{\|x\|: x \in F(\omega)\} \in \mathrm{L}_{+}^{1}$. We say that $\mathrm{F}(\cdot)$ is integrably bounded if and only if $\omega \rightarrow|F(\omega)|$ is an $\mathrm{L}_{+}^{1}-$ function. In 
this case $S_{F}^{1} \neq \emptyset$. Also using $S_{F}^{1}$ we can define a set valued integral for $F(\cdot)$ by setting $\int_{\Omega} F=\left\{\int_{\Omega} \mathrm{f}: \mathrm{f} \in \mathrm{S}_{\mathrm{F}}^{1}\right\}$.

Let $\Sigma_{0}$ be a sub- $\sigma$-field of $\Sigma$ and let $F: \Omega \rightarrow \mathrm{P}_{\mathrm{f}}(\mathrm{X})$ be a measurable multifunction s.t. $S_{F}^{1} \neq \emptyset$. Following Hiai-Umegaki [4], we define the set valued conditional expectation of $F(\cdot)$ with respect to $\Sigma_{0}$, to be the $\Sigma_{0}$-measurable multifunction $\mathrm{E}^{\Sigma_{0}} \mathrm{~F}: \Omega \rightarrow \mathrm{P}_{\mathrm{f}}(\mathrm{X})$ for which we have:

$$
{ }_{\mathrm{E}}^{1} \Sigma_{\mathrm{F}}=\mathrm{cl}\left\{\mathrm{E}^{\Sigma_{0}} \mathrm{f}_{\mathrm{f}} \in \mathrm{S}_{\mathrm{F}}^{1}\right\}
$$

the closure taken in the $L^{1}(X)$-norm. If $F(\cdot)$ is integrably bounded (resp. convex valued), then so is $\mathrm{E}^{\Sigma_{0}} \mathrm{~F}(\cdot)$.

On $P_{f}(X)$ we can define a (generalized) metric, known as the Hausdorff metric, by setting:

$$
\mathrm{h}(\mathrm{A}, \mathrm{B})=\max \{\sup (\mathrm{d}(\mathrm{a}, \mathrm{B}), \mathrm{a} \epsilon \mathrm{A}), \sup (\mathrm{d}(\mathrm{b}, \mathrm{A}), \mathrm{b} \epsilon \mathrm{B})\}
$$

Recall that $\left(\mathrm{P}_{\mathrm{f}}(\mathrm{X}), \mathrm{h}\right)$ is a complete metric space. Similarly on the space of all $\mathrm{P}_{\mathrm{f}}(\mathrm{X})$-valued, integrably bounded multifunctions, we can define a metric $\Delta(\cdot, \cdot)$ be setting $\Delta(\mathrm{F}, \mathrm{G})=\int_{\Omega} \mathrm{h}(\mathrm{F}(\omega), \mathrm{G}(\omega)) \mathrm{d} \mu(\omega)$. As usual, we identify $\mathrm{F}_{1}(\cdot)$ and $\mathrm{F}_{2}(\cdot)$, if $\mathrm{F}_{1}(\omega)=\mathrm{F}_{2}(\omega) \mu$-a.e.. The space of $\mathrm{P}_{\mathrm{f}}(\mathrm{X})$-valued, integrably bounded multifunctions, together with $\Delta(\cdot, \cdot)$ is a complete metric space.

A multifunction $\mathrm{M}: \Sigma \rightarrow \mathrm{P}_{\mathrm{wkc}}(\mathrm{X})$ is a set valued measure, if for all $\mathrm{x}^{*} \epsilon \mathrm{X}^{*}$, $\mathrm{A} \rightarrow \sigma\left(\mathrm{x}^{*}, \mathrm{M}(\mathrm{A})\right)$ is a signed measure.

Also let us recall a notion of convergence of sets that we will be using in the sequel. So let $\left\{A_{n}, A\right\}_{n \geq 1} \subseteq 2^{X} \backslash\{\emptyset\}$. We set:

$$
\text { and } \begin{aligned}
\mathrm{s}-\underline{\lim } A_{\mathrm{n}} & =\left\{\mathrm{x} \in X: \mathrm{x}_{\mathrm{n}} \stackrel{\mathrm{s}}{\longrightarrow} \mathrm{x}, \mathrm{x}_{\mathrm{n}} \in \mathrm{A}_{\mathrm{n}}, \mathrm{n} \geq 1\right\} \\
\text { alm } A_{\mathrm{n}} & =\left\{\mathrm{x} \in \mathrm{X}: \mathrm{x}_{\mathrm{k}} \stackrel{\mathrm{w}}{\longrightarrow} \mathrm{x}, \mathrm{x}_{\mathrm{k}} \in \mathrm{A}_{\mathrm{n}_{\mathrm{k}}}, \mathrm{n}_{1}<\mathrm{n}_{2}<\ldots<\mathrm{n}_{\mathrm{k}}<\ldots\right\} .
\end{aligned}
$$

Here $\mathrm{s}$ denotes the strong topology on $\mathrm{X}$ and $\mathrm{w}$ the weak topology. We say that the $A_{n}$ 's converge to $A$ is the Kuratowski-Mosco sense, denoted by $A_{n} \stackrel{K-M}{\longrightarrow} A$, if

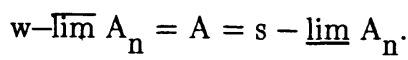


Finally, let us recall two notions of convergence of sub- $\sigma$-fields of $\Sigma$. The first was used by Nghiem [9]. So we say that $\left\{\Sigma_{n}\right\}_{n \geq 1} L^{1}(X)$-converges to $\hat{\Sigma}$ (denoted by $\left.\Sigma_{\mathrm{n}} \stackrel{\mathrm{L}^{1}(\mathrm{X})}{\longrightarrow} \dot{\Sigma}\right)$ if and only if for every $\mathrm{f} \epsilon \mathrm{L}^{1}(\mathrm{X}), \mathrm{E}^{\Sigma_{\mathrm{n}_{\mathrm{f}}} \mathrm{s}} \underset{\mathrm{E}}{\mathrm{E}} \mathrm{f}$ in $\mathrm{L}^{1}(\mathrm{X})$. If to each $\Sigma_{\mathrm{n}}$, we associate $\mathrm{E}^{\sum_{\mathrm{n}}}(\cdot) \in \mathscr{L}\left(\mathrm{L}^{1}(\mathrm{X})\right)$, then we see that this convergence of the sub- $\sigma$-fields is the convergence of the corresponding continuous, linear operators in the strong operator topology on $\mathscr{L}\left(\mathrm{L}^{1}(\mathrm{X})\right)$ (pointwise convergence).

The second notion was used by Fetter [3]. So we may say that $\lim \Sigma_{\mathrm{n}}=\hat{\Sigma}$ if and

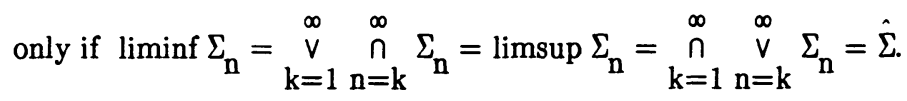

\section{3) SINGLE VALUED CONDITIONAL EXPECTATION}

Let $(\Omega, \Sigma, \mu)$ be a complete probability space, $\left\{\Sigma_{n}, \hat{\Sigma}\right\}_{n \geq 1}$ sub- $\sigma-$ fields of $\Sigma$ and $\mathrm{X}$ a Banach space.

THEOREM 3.1: If $\lim \Sigma_{\mathrm{n}}=\hat{\Sigma}$, then $\Sigma_{\mathrm{n}} \stackrel{\mathrm{L}^{1}(\mathrm{X})}{\longrightarrow} \hat{\Sigma}$

PROOF: Let $\mathrm{K}_{\mathrm{n}}=\underset{\mathrm{k}=\mathrm{n}}{\mathrm{V}} \Sigma_{\mathrm{k}}$ and $\mathrm{L}_{\mathrm{n}}=\bigcap_{\mathrm{k}=\mathrm{n}}^{\infty} \Sigma_{\mathrm{k}}$. Clearly $\underset{n=1}{n} \mathrm{~K}_{\mathrm{n}}=\underset{\mathrm{n}=1}{\mathrm{~V}} \mathrm{~L}_{\mathrm{n}}=\hat{\Sigma}$ and for every $n \geq 1$, we have $L_{n} \subseteq \Sigma_{n} \subseteq K_{n}$. Let $f \in L^{1}(X)$. We have:

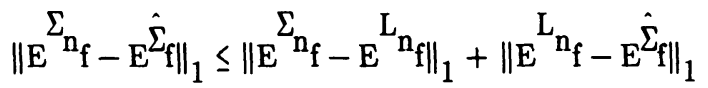

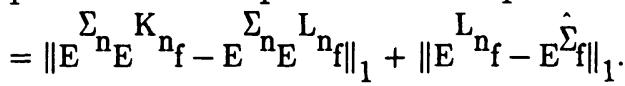

Recall that the vector valued conditional expectation is an $\mathrm{L}^{1}(\mathrm{X})$-contraction. So we have:

$$
\begin{aligned}
& \left\|E^{\sum_{n}} K^{K} n_{f-E}{ }^{\sum_{n}} E^{L} n_{f \|_{1}} \leq\right\| E^{K} n_{f-E}{ }^{L} n_{f \|_{1}}
\end{aligned}
$$

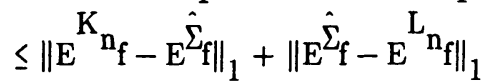

So finally we have:

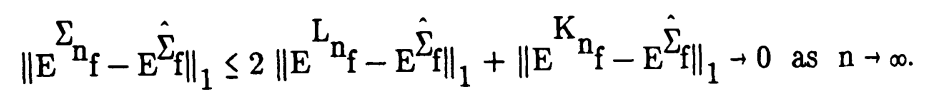

from the "Neveu-Ionescu Tulcea theorem" (see section 1). Therefore $\Sigma_{n} \stackrel{L^{1}(X)}{\longrightarrow} \hat{\Sigma}$ as claimed by the theorem.

THEOREM 3.2: If $\Sigma_{\mathrm{n}} \stackrel{\mathrm{L}^{1}(\mathrm{X})}{\longrightarrow} \hat{\Sigma}$ and $\mathrm{f}_{\mathrm{n}} \stackrel{\mathrm{s}}{\longrightarrow} \mathrm{f}$ in $\mathrm{L}^{1}(\mathrm{X})$,

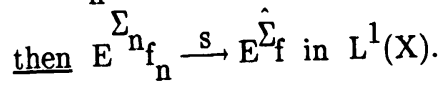


PROOF: For every $\mathrm{n} \geq 1$, we have:

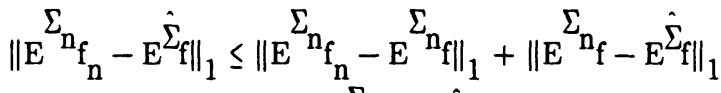

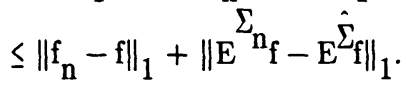

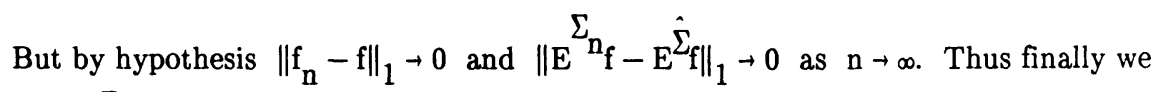

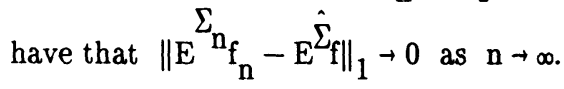

Q.E.D.

Next we will determine a sufficient condition for the $\mathrm{L}^{1}(\mathrm{X})$-convergence of a sequence $\left\{\Sigma_{n}\right\}_{n \geq 1}$ of sub- $\sigma$-fields of $\Sigma$.

For this we will need a stronger hypothesis on the Banach space $\mathrm{X}$. So assume that $\mathrm{X}$ is strictly convex.

THEOREM 3.3: If for every A $\epsilon \Sigma$ and for every $x \in X,\left\{E^{\Sigma} \chi_{A}(\cdot) x\right\}_{n \geq 1}$ is $\mathrm{L}^{1}(\mathrm{X})$-convergent, then there exists $\hat{\Sigma}$ a sub- $\sigma$-field of $\Sigma$ s.t. $\Sigma_{n} \stackrel{L^{1}(X)}{\longrightarrow} \hat{\Sigma}$.

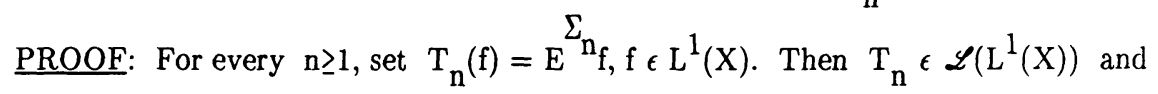
$\left\|T_{n}\right\| \leq 1$ for all $n \geq 1$. Clearly from our hypothesis, given any simple function $s(\cdot)$, $\left\{T_{n}(s)\right\}_{n \geq 1}$ is $L^{1}(X)$-convergent. We claim that for every $f \in L^{1}(X),\left\{T_{n}(f)\right\}_{n \geq 1}$ is $L^{1}(X)$-convergent too. To this end this $\epsilon>0$ be given. We can find $s(\cdot)$ simple function s.t. $\|\mathrm{f}-\mathrm{s}\|_{1}<\epsilon$. Also there exists $\mathrm{n}_{0} \geq 1$ s.t. for $\mathrm{n}, \mathrm{m} \geq \mathrm{n}_{0}$, we have $\| \mathrm{T}_{\mathrm{n}}(\mathrm{s})-$ $T_{m}(s) \|<\epsilon / 3$. So finally for $n, m \geq n_{0}$ we have:

$$
\begin{gathered}
\left\|\mathrm{T}_{\mathrm{n}}(\mathrm{f})-\mathrm{T}_{\mathrm{m}}(\mathrm{f})\right\|_{1} \leq\left\|\mathrm{T}_{\mathrm{n}}(\mathrm{f})-\mathrm{T}_{\mathrm{n}}(\mathrm{s})\right\|_{1}+\left\|\mathrm{T}_{\mathrm{n}}(\mathrm{s})-\mathrm{T}_{\mathrm{m}}(\mathrm{s})\right\|_{1}-\left\|\mathrm{T}_{\mathrm{m}}(\mathrm{s})-\mathrm{T}_{\mathrm{m}}(\mathrm{f})\right\|_{1} \\
\leq 2\|\mathrm{f}-\mathrm{s}\|_{1}+\left\|\mathrm{T}_{\mathrm{n}}(\mathrm{s})-\mathrm{T}_{\mathrm{m}}(\mathrm{s})\right\|<\epsilon .
\end{gathered}
$$

Therefore $\left\{T_{n}(f)\right\}_{n \geq 1}$ is $L^{1}(X)$-Cauchy, thus it converges in $L^{1}(X)$ to $T(f)$ and $\mathrm{T} \epsilon \mathscr{L}\left(\mathrm{L}^{1}(\mathrm{X})\right.$ ) (see Kato [5], p. 150). It is easy to see that $\mathrm{T}(\cdot)$ is idempotent and $\mathrm{L}^{1}(\mathrm{X})$-contractive. So invoking the result of Landers-Rogge [6], we deduce that there exists $\hat{\Sigma}$ a sub- $\sigma$-field of $\Sigma$ s.t. $T=E^{\hat{\Sigma}}$. Hence $\Sigma_{\mathrm{n}} \stackrel{\mathrm{L}^{1}(\mathrm{X})}{\longrightarrow} \hat{\Sigma}$ as claimed by the theorem.

\section{4) SET VALUED CONDITIONAL EXPECTATION}

Here we extend the work of section 3 to set valued random variables. 
In this section $(\Omega, \Sigma, \mu)$ is a complete probability space and $\mathrm{X}$ a separable Banach space. Additional hypotheses will be introduced as needed.

We start with an interesting observation concerning set valued conditional expectations.

THEOREM 4.1: If $\mathrm{X}^{*}$ is separable, $\Sigma_{0}$ is a sub- $\sigma$-field of $\Sigma$ and

$$
\mathrm{F}: \Omega \rightarrow \mathrm{P}_{\text {wkc }}(\mathrm{X}) \text { is }
$$

integrably bounded,

$$
\text { then } \mathrm{E}^{\Sigma_{0}} \mathrm{~F}(\omega) \in \mathrm{P}_{\text {wkc }}(\mathrm{X}) \mu-\text { a.e.. }
$$

PROOF: From the corollary to proposition 3.1 of [10], we have that for all $A \in \Sigma_{0}$, $\mathrm{M}(\mathrm{A})=\int_{\mathrm{A}} \mathrm{F}(\omega) \mathrm{d} \mu(\omega)=\left\{\int_{\mathrm{A}} \mathrm{f}(\omega) \mathrm{d} \mu(\omega): \mathrm{f} \in \mathrm{S}_{\mathrm{F}}^{1}\right\} \in \mathrm{P}_{\text {wkc }}(\mathrm{X})$. Using theorem 2.2 of Hiai-Umegaki [4], we have:

$$
\begin{aligned}
& \sigma\left(\mathrm{x}^{*}, \mathrm{M}(\mathrm{A})\right)=\int_{\mathrm{A}} \sigma\left(\mathrm{x}^{*}, \mathrm{~F}(\omega)\right) \mathrm{d} \mu(\omega) \\
& \Rightarrow \mathrm{A} \rightarrow \sigma\left(\mathrm{x}^{*}, \mathrm{M}(\mathrm{A})\right) \text { is a signed measure, } \\
& \Rightarrow \mathrm{M}(\cdot) \text { is a set valued measure. }
\end{aligned}
$$

Apply theorem 3 of Costé [1] to get $\mathrm{G}: \Omega \rightarrow \mathrm{P}_{\text {wkc }}(\mathrm{X}) \Sigma_{0}$-integrably bounded s.t.

$$
\begin{aligned}
& \mathrm{M}(\mathrm{A})=\int_{\mathrm{A}} \mathrm{G}(\omega) \mathrm{d} \mu(\omega) \\
& \rightarrow \int_{\mathrm{A}} \mathrm{E}^{\Sigma_{0}} \mathrm{~F}^{\prime}(\omega) \mathrm{d} \mu(\omega)=\int_{\mathrm{A}} \mathrm{G}(\omega) \mathrm{d} \mu(\omega) \\
& \Rightarrow \int_{\mathrm{A}} \sigma\left(\mathrm{x}^{*}, \mathrm{E}^{\Sigma_{0}} \mathrm{~F}(\omega)\right) \mathrm{d} \mu(\omega)=\int_{\mathrm{A}} \sigma\left(\mathrm{x}^{*}, \mathrm{G}(\omega)\right) \mathrm{d} \mu(\omega) \\
& \Rightarrow \sigma\left(\mathrm{x}^{*}, \mathrm{E}^{\Sigma_{0}} \mathrm{~F}(\omega)\right)=\sigma\left(\mathrm{x}^{*}, \mathrm{G}(\omega)\right) \\
& \text { for all } \omega \in \Omega \backslash \mathrm{N}\left(\mathrm{x}^{*}\right), \mu\left(\mathrm{N}\left(\mathrm{x}^{*}\right)\right)=0
\end{aligned}
$$

Let $\left\{\mathrm{x}_{\mathrm{n}}^{*}\right\}_{\mathrm{n} \geq 1}$ be dense in $\mathrm{X}^{*}$ and let $\mathrm{N}=\underset{\mathrm{n} \geq 1}{\mathrm{U}} \mathrm{N}\left(\mathrm{x}_{\mathrm{n}}^{*}\right), \mu(\mathrm{N})=0$. Let $\mathrm{x}^{*} \in \mathrm{X}^{*}$ and pick $\left\{\mathrm{x}_{\mathrm{k}}^{*}\right\}_{\mathrm{k} \geq 1} \subseteq\left\{\mathrm{x}_{\mathrm{n}}^{*}\right\}_{\mathrm{n} \geq 1}$ s.t. $\mathrm{x}_{\mathrm{k}}^{*} \stackrel{\mathrm{s}}{\longrightarrow} \mathrm{x}^{*}$. Then for $\omega \in \Omega \backslash N$, we have:

$$
\begin{aligned}
& \left|\sigma\left(\mathrm{x}^{*}, \mathrm{E}^{\Sigma_{0}} \mathrm{~F}(\omega)\right)-\sigma\left(\mathrm{x}^{*}, \mathrm{G}(\omega)\right)\right| \\
& \leq\left|\sigma\left(\mathrm{x}^{*}, \mathrm{E}^{\Sigma_{0}} \mathrm{~F}(\omega)\right)-\sigma\left(\mathrm{x}_{\mathrm{k}}^{*}, \mathrm{E}^{\Sigma_{0}} \mathrm{~F}(\omega)\right)\right|+\left|\sigma\left(\mathrm{x}_{\mathrm{k}}^{*}, \mathrm{G}(\omega)\right)-\sigma\left(\mathrm{x}^{*}, \mathrm{G}(\omega)\right)\right| \rightarrow 0 \text { as } \mathrm{k} \rightarrow \infty
\end{aligned}
$$

So for all $\omega \in \Omega \backslash N, \mu(\mathrm{N})=0$, we have:

$$
\begin{aligned}
& \sigma\left(\mathrm{x}^{*}, \mathrm{E}^{\Sigma_{0}} \mathrm{~F}(\omega)\right)=\sigma\left(\mathrm{x}^{*}, \mathrm{G}(\omega)\right) \\
& \Rightarrow \mathrm{E}^{{ }^{2}} \mathrm{~F}(\omega)=\mathrm{G}(\omega) \in \mathrm{P}_{\text {wkc }}(\mathrm{X}) \mu-\text { a.e. }
\end{aligned}
$$


Next we will derive a set valued version of theorem 3.2. For this we will need the following simple lemmata.

LEMMA 4.1: If $\Sigma_{0}$ is a sub- $\sigma$-field of $\Sigma, f \in \mathrm{L}^{1}(\mathrm{X})$ and $\mathrm{v} \in \mathrm{L}^{\infty}\left(\Sigma_{0}, \mathrm{X}^{*}\right)$,

$$
\text { then } \int_{\Omega}(\mathrm{f}(\omega), \mathrm{v}(\omega)) \mathrm{d} \mu(\omega)=\int_{\Omega}\left(\mathrm{E}^{\left.\Sigma^{0} \mathrm{f}(\omega), \mathrm{v}(\omega)\right) \mathrm{d} \mu(\omega)}\right. \text {. }
$$

PROOF: Let $\mathrm{v}(\omega)=\chi_{\mathrm{A}}(\omega) \mathrm{x}^{*}$ with $\mathrm{A} \epsilon \Sigma_{0}$ and $\mathrm{x}^{*} \epsilon \mathrm{X}^{*}$. Then we have:

$$
\begin{aligned}
& \int_{\Omega}\left(\mathrm{E}^{\Sigma_{0}} \mathrm{f}(\omega), \chi_{\mathrm{A}}(\omega) \mathrm{x}^{*}\right) \mathrm{d} \mu(\omega)=\int_{\mathrm{A}}\left(\mathrm{E}^{\Sigma_{0}} \mathrm{f}(\omega), \mathrm{x}^{*}\right) \mathrm{d} \mu(\omega) \\
& =\int_{\mathrm{A}} \mathrm{E}^{\Sigma_{0}}\left(\mathrm{f}(\omega), \mathrm{x}^{*}\right) \mathrm{d} \mu(\omega)=\int_{\Omega} \chi_{\mathrm{A}}(\omega) \mathrm{E}^{\Sigma_{0}}\left(\mathrm{f}(\omega), \mathrm{x}^{*}\right) \mathrm{d} \mu(\omega) \\
& =\int_{\Omega} \mathrm{E}^{\Sigma_{0}}\left(\mathrm{f}(\omega), \chi_{\mathrm{A}}(\omega) \mathrm{x}^{*}\right) \mathrm{d} \mu(\omega)=\int_{\Omega}\left(\mathrm{f}(\omega), \chi_{\mathrm{A}}(\omega) \mathrm{x}^{*}\right) \mathrm{d} \mu(\omega) .
\end{aligned}
$$

So the lemma is true for countably valued $\mathrm{v}(\cdot)$ belonging in the Lebesgue-Bochner space $\mathrm{L}^{\infty}\left(\Sigma_{0}, \mathrm{X}^{*}\right)$. But from corollary 3, p. 42, of Diestel-Uhl [2], we know that these functions are dense in $L^{\infty}\left(\Sigma_{0}, X^{*}\right)$. So by a simple density argument, we conclude that the lemma holds for all $v \in L^{\infty}\left(\Sigma_{0}, X^{*}\right)$.

Q.E.D.

LEMMA 4.2: If $\Sigma_{0}$ is a sub- $\sigma$-field of $\Sigma, f \in \mathrm{L}^{1}\left(\Sigma_{0}, \mathrm{X}\right)$ and $\mathrm{v} \in \mathrm{L}^{\infty}\left(\mathrm{X}^{*}\right)$,

$$
\text { then } \int_{\Omega}(\mathrm{f}(\omega), \mathrm{v}(\omega)) \mathrm{d} \mu(\omega)=\int_{\Omega}\left(\mathrm{f}(\omega), \mathrm{E}^{\Sigma_{0}} \mathrm{v}(\omega)\right) \mathrm{d} \mu(\omega) \text {. }
$$

PROOF: As in lemma 4.1, we can check that the result holds for $f(\cdot)$ being a simple function. But recall that simple functions are dense in $L^{1}\left(\Sigma_{0}, X\right)$. So the lemma follows by density.

Q.E.D.

From Diestel-Uhl [2], theorem 1, p. 98, we know that if $\mathrm{X}^{*}$ is separable, then $\left[\mathrm{L}^{1}(\mathrm{X})\right]^{*}=\mathrm{L}^{\infty}\left(\mathrm{X}^{*}\right)$ and if $\mathrm{f} \epsilon \mathrm{L}^{1}(\mathrm{X}), \mathrm{v} \in \mathrm{L}^{\infty}\left(\mathrm{X}^{*}\right)$, then their duality brackets are defined by $<f, v>=\int_{\Omega}(f(\omega), v(\omega)) d \mu(\omega)$.

THEOREM 4.2: If $\mathrm{X}^{*}$ is separable, $\Sigma_{\mathrm{n}} \stackrel{\mathrm{L}^{1}(\mathrm{X})}{\longrightarrow} \hat{\Sigma}, \mathrm{F}_{\mathrm{n}} \mathrm{F}: \Omega \rightarrow \mathrm{P}_{\text {wkc }}(\mathrm{X})$ are integrably bounded multifunctions s.t. $S_{F_{n}}^{1} \stackrel{K-M}{\longrightarrow} S_{F}^{1}$ and $\underset{n \geq 1}{U} S_{F_{n}}^{1}$ is relatively $\mathrm{w}$-compact in $\mathrm{L}^{1}(\mathrm{X})$, then $\mathrm{S}_{\mathrm{E}}^{1} \Sigma_{\mathrm{n}_{\mathrm{F}}} \stackrel{\mathrm{K}-\mathrm{M}}{\longrightarrow} \mathrm{S}_{\mathrm{E}^{1}} \hat{\Sigma}_{\mathrm{F}}$ as $\mathrm{n} \rightarrow \infty$.

PROOF: First let $g \in \mathrm{S}_{E^{1}}^{1} \hat{\Sigma}_{\mathrm{F}}$. From proposition 3.1 of [10], we know that $\mathrm{S}_{\mathrm{F}}^{1}$

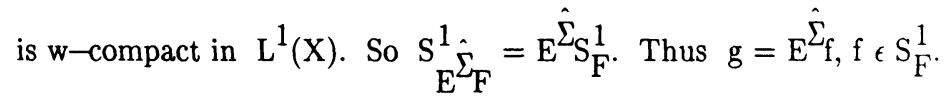


Since by hypothesis $S_{F_{n}}^{1} \stackrel{K-M}{\longrightarrow} S_{F}^{1}$, we can find $f_{n} \in S_{F_{n}}^{1} n \geq 1$ s.t. $f_{n} \stackrel{s}{\longrightarrow} f$ in $L^{1}(X)$.

Then theorem 3.2 tells us that $\mathrm{E}^{\sum_{\mathrm{n}_{\mathrm{f}}}} \stackrel{\mathrm{s}}{\longrightarrow} \mathrm{E}^{\hat{\Sigma}_{\mathrm{f}}}$ in $\mathrm{L}^{1}(\mathrm{X})$ and for every $\mathrm{n} \geq 1 \quad \mathrm{E}^{\sum_{\mathrm{f}_{\mathrm{n}}} \epsilon}$ $\mathrm{S}^{1} \Sigma_{\mathrm{n}_{\mathrm{n}}}$ Therefore we deduce that:

$$
\mathrm{S}_{\mathrm{E}}^{1} \hat{\Sigma}_{\mathrm{F}} \subseteq \mathrm{s}-\underline{\lim } \mathrm{S}_{\mathrm{E}}^{1} \Sigma_{\mathrm{n}_{\mathrm{F}}}
$$

Next let $g \in \mathrm{w}-\sqrt{\lim } \mathrm{S}_{\mathrm{E}}^{1} \Sigma_{\mathrm{n}_{\mathrm{n}}}$. By definition, we can find $\mathrm{g}_{\mathrm{k}} \in \mathrm{S}_{\mathrm{E}}^{1} \Sigma_{\mathrm{n}_{\mathrm{kF}}}$ s.t.

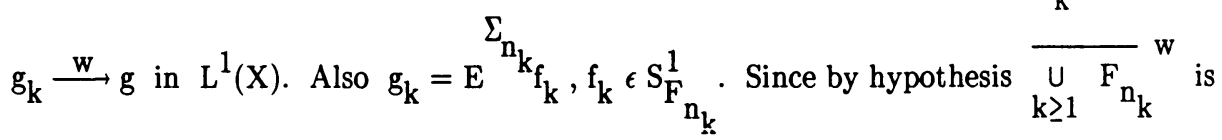
$\mathrm{w}$-compact in $\mathrm{L}^{1}(\mathrm{X})$, by passing to a subsequence if necessary, we may assume that $\mathrm{f}_{\mathrm{k}} \stackrel{\mathrm{w}}{\longrightarrow} \mathrm{f}$ in $\mathrm{L}^{1}(\mathrm{X})$. Since $\mathrm{S}_{\mathrm{F}_{\mathrm{n}}}^{1} \stackrel{\mathrm{K}-\mathrm{M}}{\longrightarrow} \mathrm{S}_{\mathrm{F}}^{1}$, we get that $\mathrm{f} \in \mathrm{S}_{\mathrm{F}}^{1}$. Let $\mathrm{v}(\cdot) \in \mathrm{L}^{\infty}\left(X^{*}\right)$ $=\left[\mathrm{L}^{1}(\mathrm{X})\right]^{*}$ and denote by $<\cdot, \cdot>$ the duality brackets for the pair $\left(\mathrm{L}^{1}(\mathrm{X}), \mathrm{L}^{\infty}\left(\mathrm{X}^{*}\right)\right)$. From lemmata 4.1 and 4.2 we have:

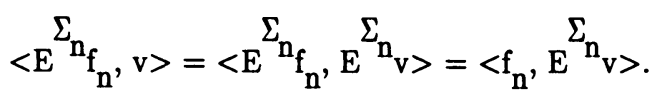

By hypothesis we have $\mathrm{E}^{\sum_{\mathrm{n}}} \stackrel{\mathrm{s}}{\longrightarrow} \mathrm{E}^{\hat{\Sigma}} \mathrm{v}$ in $\mathrm{L}^{1}(\mathrm{X})$. Also note that for all $\mathrm{n} \geq 1$ $\left\|\mathrm{E}^{\sum_{\mathrm{n}}} \mathrm{v}(\omega)\right\| \leq \mathrm{E}^{\mathrm{n}_{\mathrm{n}}}\|\mathrm{v}(\omega)\| \leq\|\mathrm{v}\|_{\infty} \mu-$ a.e.. So invoking lemma 4.2 of [12], we get:

$<f_{n}, E^{\sum_{v}}>\rightarrow<f, E^{\hat{\Sigma}_{v}}$.

Again through lemmata 4.1 and 4.2 we get:

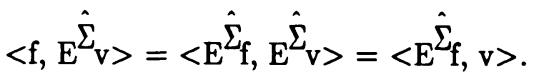

Thus for every $v \in L^{\infty}\left(X^{*}\right)=\left[L^{1}(X)\right]^{*}$, we have:

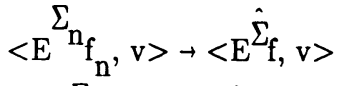

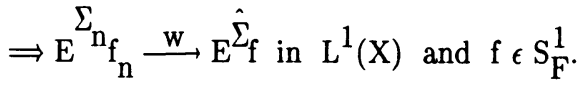




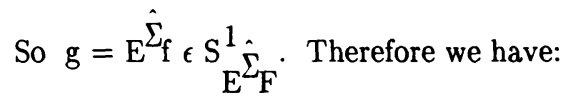

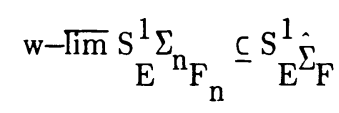

From (1) and (2) above and since we always have s-lim $\mathrm{S}_{\mathrm{E}}^{1} \Sigma_{\mathrm{n}_{\mathrm{F}}} \subseteq \mathrm{w}-\sqrt{\mathrm{im}} \mathrm{S}_{\mathrm{E}}^{1} \Sigma_{\mathrm{n}_{\mathrm{F}}}$, we conclude that $\mathrm{S}_{\mathrm{S}}^{1} \sum_{\mathrm{n}_{\mathrm{F}}} \stackrel{\mathrm{K}-\mathrm{M}}{\longrightarrow} \mathrm{S}_{\mathrm{E}}^{1} \hat{\mathrm{E}}_{\mathrm{F}}$ as $\mathrm{n} \rightarrow \infty$.

Q.E.D.

REMARKS: (a) If for all $n \geq 1, F_{n}=F: \Omega \rightarrow P_{w k c}(X)$ and is integrably bounded, then the hypotheses of theorem 4.2 are automatically satisfied. Similarly if for all $n \geq 1$ $F_{n}(\omega) \subseteq W(\omega) \mu-$ a.e. with $W: \Omega \rightarrow P_{\text {wkc }}(X)$ integrably bounded.

(b) Conditions that guarantee that $S_{F_{n}}^{1} \stackrel{K-M}{\longrightarrow} S_{F}^{1}$ can be found in [11] (theorem 4.4).

Finally by strengthening the hypotheses on $\mathrm{F}_{\mathrm{n}}(\cdot)$ and dropping the separability requirement on $\mathrm{X}^{*}$, we can prove convergence in the $\Delta(\cdot, \cdot)$ metric.

THEOREM 4.3: If $\lim \Sigma_{\mathrm{n}}=\hat{\Sigma}$ and $\mathrm{F}_{\mathrm{n}}, \mathrm{F}: \Omega \rightarrow \mathrm{P}_{\mathrm{kc}}(\mathrm{X})$ are integrably bounded

$$
\begin{aligned}
& \text { multifunctions s.t. } F_{\mathrm{n}} \stackrel{\Delta}{\longrightarrow} \mathrm{F}, \\
& \text { then } \Delta\left(\mathrm{E}^{\sum_{\mathrm{n}}} \mathrm{F}_{\mathrm{n}}, \mathrm{E}^{\left.\Sigma_{\mathrm{F}}\right) \rightarrow 0} \text { as } \mathrm{n} \rightarrow \infty .\right.
\end{aligned}
$$

PROOF: Using Rädstrom's embedding theorem [13] (theorem 2), we can embed $\mathrm{P}_{\mathrm{kc}}(\mathrm{X})$ isometrically as a convex cone in a separable Banach space $\hat{\mathrm{X}}$. Then $\mathrm{F}_{\mathrm{n}}(\cdot), \mathrm{F}(\cdot)$ $\mathrm{n} \geq 1$ can be viewed as $\hat{\mathrm{X}}$-valued random variables and $\mathrm{E}^{{ }^{\mathrm{n}_{\mathrm{n}}}} \mathrm{F}(\cdot), \mathrm{E}^{\hat{\Sigma}_{\mathrm{F}}(\cdot)}$ are $\mathrm{P}_{\mathrm{kc}}(\mathrm{X})$-valued, integrably bounded. Then if by $\mathrm{j}(\cdot)$ we denote the embedding of $\mathrm{P}_{\mathrm{kc}}(\mathrm{X})$ in $\hat{\mathrm{X}}$, theorem 3.6 of Hiai-Umegaki [4] and theorem 3.1 of this paper, tell us that

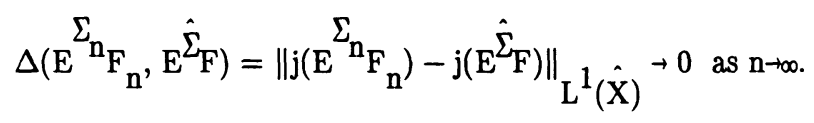

Q.E.D.

ACKNOWLEDGEMENT: The author is indebted to the referee for his suggestions and remarks that improved the presentation. This research was supported by N.S.F. Grant D.M.S. -8802688 


\section{REFERENCES:}

1) A. Costé: $\quad$ "La propierté de Radon-Nikodym en integration multivoque." C.R. Acad. Sci. Paris, t. 280 (1975), pp. 1515-1518.

2) J. Diestel-J. Uhl:"Vector Measures" Math. Surveys, Vol. 15, A.M.S., Providence, Rhode Island (1977)

3) H. Fetter: $\quad$ "On the continuity of conditional expectations" J. Math. Anal. Appl. 61 (1977), pp. 227-231.

4) F. Hiai-H. Umegaki: "Integrals, conditional expectations and martingales of multivalued functions" J. Multiv. Anal. 7 (1977), pp. 149-182.

5) T. Kato: $\quad$ "Perturbation Theory for Linear Operators" Springer, Berlin (1976).

6) D. Landers-L. Rogge: "Characterization of conditional expectation operators for Banach-valued functions" Proc. Amer. Math. Soc. $\underline{11}$ (1981), pp. 107-110.

7) M. Metivier: $\quad$ "Semimartingales" De Gruyter, Berlin (1982).

8) J. Neveu: "Discrete Parameter Martingales" North Holland, Amsterdam (1975).

9) D.N. Ngheim: "Convergence forte des éspérances conditionelles et des projecteurs d'un espace de Hilbert" Ann. Inst. H. Poincaré, Vol. VI (1970), pp. 9-13.

10) N.S. Papageorgiou: "On the theory of Banach space valued multifunctions. Part 1: Integration and conditional expectation" J. Multiv. Anal. 17 (1985), pp. 185-207.

11) N.S. Papageorgiou: "Convergence theorems for Banach space valued integrable multifunctions" Intern. J. Math and Math. Sci. 10 (1987), pp. 433-442.

12) N.S. Papageorgiou-D. Kandilakis: "Convergence in approximation and nonsmooth analysis" J. Approx. Theory 49 (1987), pp. 41-54.

13) H. Radström: "An embedding theorem for spaces of convex sets" Proc. Amer. Math. Soc. 3 (1954), pp. 165-169.

14) D. Wagner: $\quad$ "Survey of measurable selection theorem" SIAM J. Control. Optim. 15 (1977), pp. 859-903. 


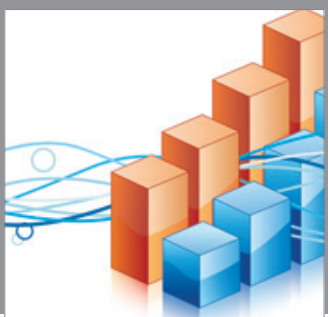

Advances in

Operations Research

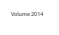

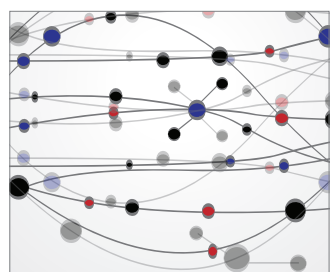

\section{The Scientific} World Journal
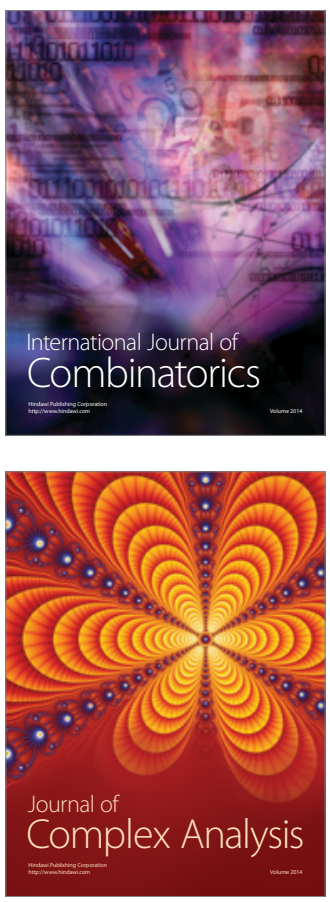

International Journal of

Mathematics and

Mathematical

Sciences
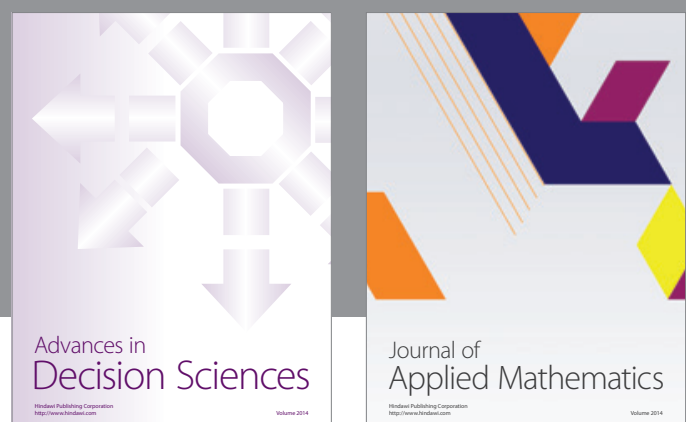

Journal of

Applied Mathematics
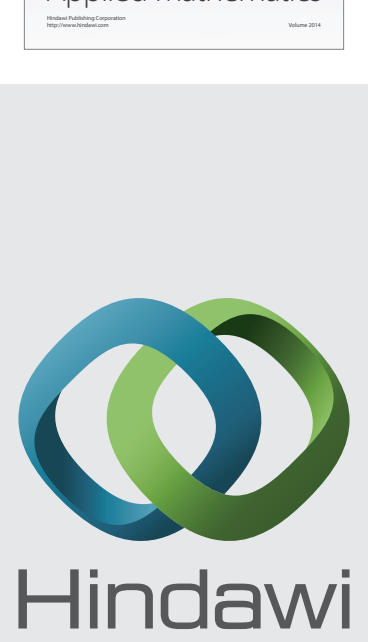

Submit your manuscripts at http://www.hindawi.com
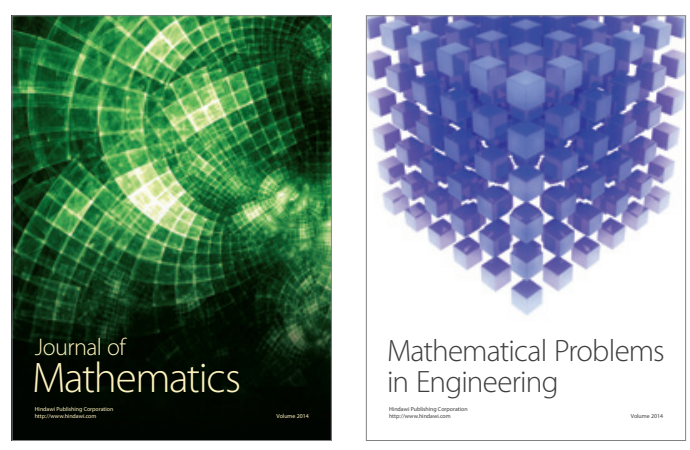

Mathematical Problems in Engineering
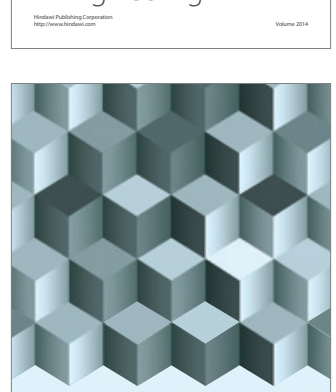

Journal of

Function Spaces
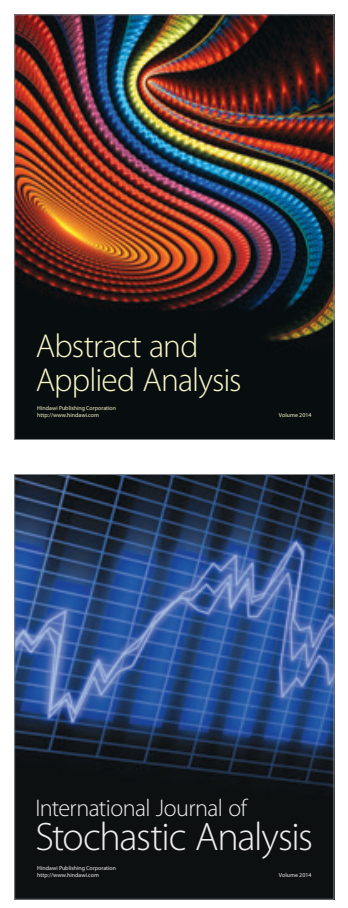

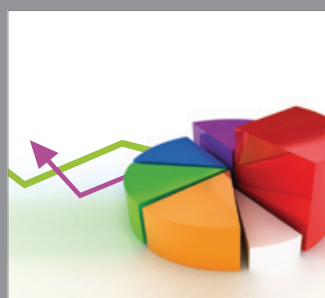

ournal of

Probability and Statistics

Promensencen
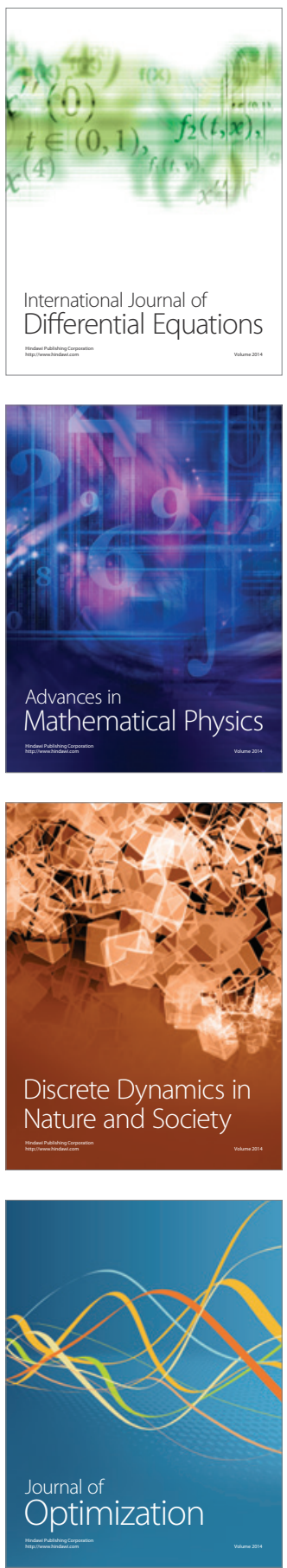